\title{
A MODEL TO OPTIMIZE PAYLOADS AT PFG BUILDING GLASS
}

\author{
R. Brits and P.J. Conradie \\ Department of Industrial and Systems Engineering \\ University of Pretoria \\ pconradi@postino.up.ac.za
}

\begin{abstract}
While improving customer service by allowing user definable mixed load orders of their plate glass product, PFG Building Glass was confronted with a problem of calculating the feasibility and optimum load layout for transporting the glass, without transgressing the regulatory requirements. In this article the development of an integrated solution is discussed, including the definition of a mathematical model that calculates the axle weights, the optimization model based on linear programming, as well as the user interface for their current information system.
\end{abstract}

The solution enables the company to proceed with e-commerce service to clients, since the system can evaluate the transport feasibility and give real time feedback to clients.

\section{OPSOMMING}

Die uitbreiding van kliëntediens by PFG Building Glass om bestellings van gemengde glasplaatprodukte per vrag te aanvaar, het die onderneming voor ' $n$ uitdaging geplaas om te bereken of sulke bestellings binne die wetlike regulasie vervoer sal kan word. Hierdie artikel bespreek die ontwikkeling van ' $n$ geïntegreede oplossing wat bestaan uit ' $n$ wiskundige model wat die gewig per as bereken, 'n optimiseringsmodel wat die vraguitleg bepaal en op liniêre programmeringsbeginsels gebaseer is, sowel as die gebruikersintervlak met die onderneming se bestaande inligtingstelsel.

Hierdie ontwikkeling stel die onderneming instaat om 'n e-besigheidsdiens vir kliente daar te stel, aangesien terugvoer oor die uitvoerbaarheid van ' $n$ bestelling uit ' $n$ vervoeroogpunt intyds aan die kliënt gekommunikeer kan word. 


\section{INTRODUCTION}

Up to about 4 years ago PFG Building Glass delivered their product (sheets of flat glass) on a multitude of specialized distribution equipment, designed to cater for the full product range. A new concept of "mixed loads" was developed in which a customer could replenish his full product range with one truckload of glass. The advantage for PFG was a major reduction in distribution equipment.

A truckload that is made up of a mix of products, specified by the customer, created new problems and challenges. Approximately $27 \%$ of orders caused endless disruptions within the business. It was a typical case of the Pareto principle where $20 \%$ of the loads caused $80 \%$ of the problems. These problems had to be addressed by staff that had a high level of product and equipment knowledge, as well as experience on how trucks were loaded.

The glass sheets that PFG produces come in many different dimensions, thicknesses, packsizes and packaging. For mixed loads staff capturing orders required a tool to calculate whether an order could fit onto a truck and if it was possible and safe to load the glass given equipment constraints.

A problem encountered with the introduction of mixed loads was that the axle exceeded above government regulation values. Although it is possible to calculate the total weight of the load, the positioning of the glass on the trailer bed determines the axle weights, while the total weight of the load was often within legal limits, the individual axle weights were not. To counter this, the total payload was reduced for loads that were doubtful. This had cost implications, often the truck would be sent back from the weighbridge for the load to be rearranged. This impacted on service levels.

\section{TERMINOLOGY AND DEFINITIONS}

Axle force/Axle weight: The reaction force exerted by the trailer and/or hauler through their axles to the wheels and other contact surfaces.

Glass packs/Packs: The collection of a number of glass plates. The number of plates in a pack is a function of the substance or thickness of a single glass plate. Refer to Figure 1.

Load Layout: The way in which the glass packs are arrange on a 28 - or 30-ton trailer. The load layout has a direct effect on the axle weights. Refer to Figure 1.

Zones: The number of rows on a 28 - or 30 -ton trailer. The number of zones is a factor of the trailer type, glass length and number of packs ordered. Refer to Figure 1.

Figure 1 shows 5 glass packs placed on the left hand side of zone 1. From the figure, it can be seen that the 5 packs differ in dimension and thus in weight. The figure also shows the names of the trailer components. 


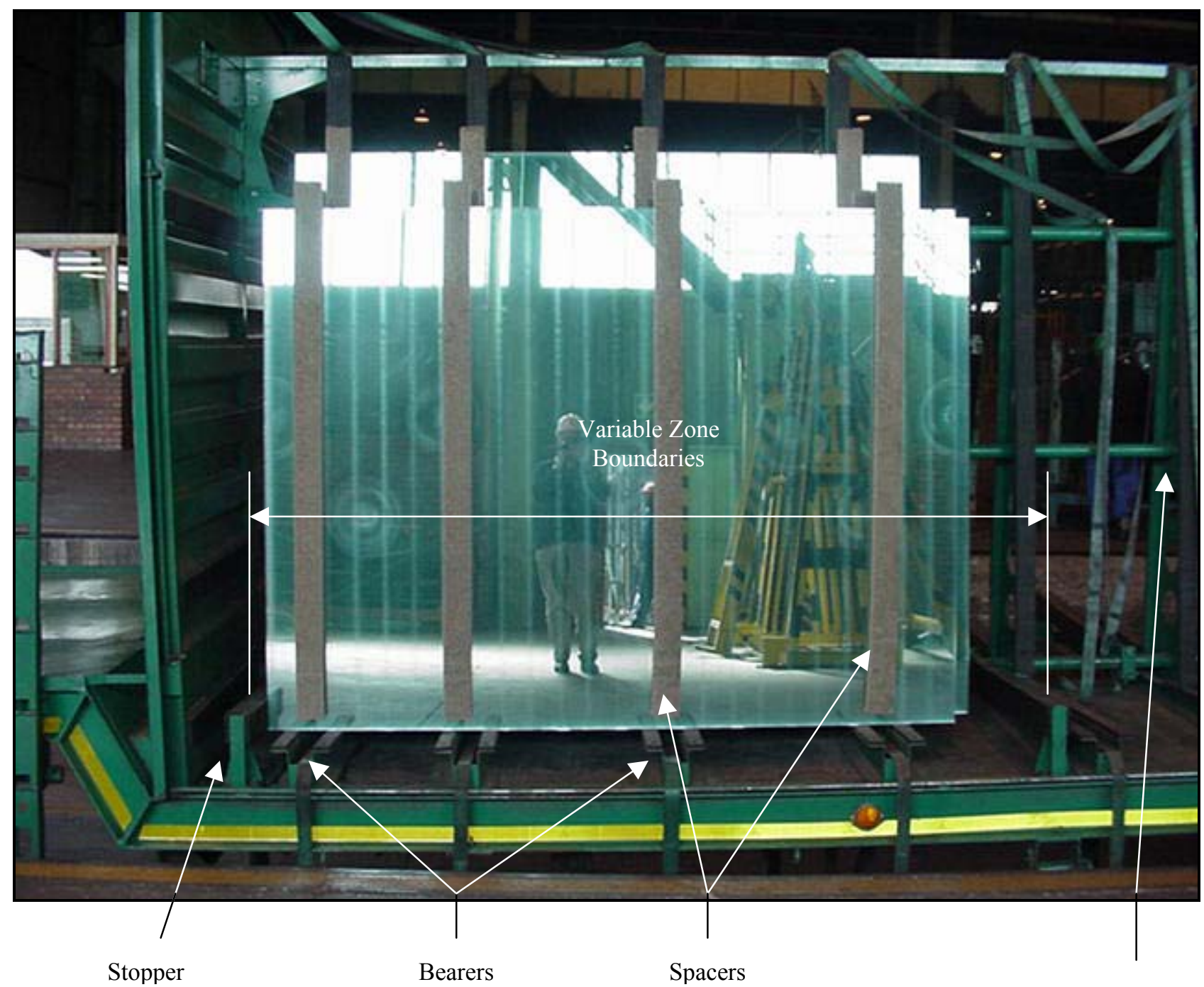

Figure 1: 5-glass packs placed in zone 1

\section{PROBLEM STATEMENT}

To improve the loading of mixed loads, a model had to be developed with the objective of determining the optimal load layout for a given load, while adhering to government regulations and loading rules. The total solution development entailed three steps:

1. Development of a mathematical model with which the axle weights can be calculated.

2. Development of an optimization model with which the load layout can be determined.

3. Integration of the models into the current information system.

The effects of load placement and the resulting axle weights can readily be illustrated by a simple example. Figure 2 illustrates the problem schematically. The maximum allowable payload for the trailer is 29 tons. The trailer has only been loaded to 27 tons. Figure 2 (a) shows the incorrect placement of loads, which results in overweight rear trailer axles. In Figure 2 (b), the same payload is placed, but with a different load arrangement. The difference between the axle weights is less than that of the first scenario. The rearrangement of the load layout has thus produced a more acceptable axle weight combination. 


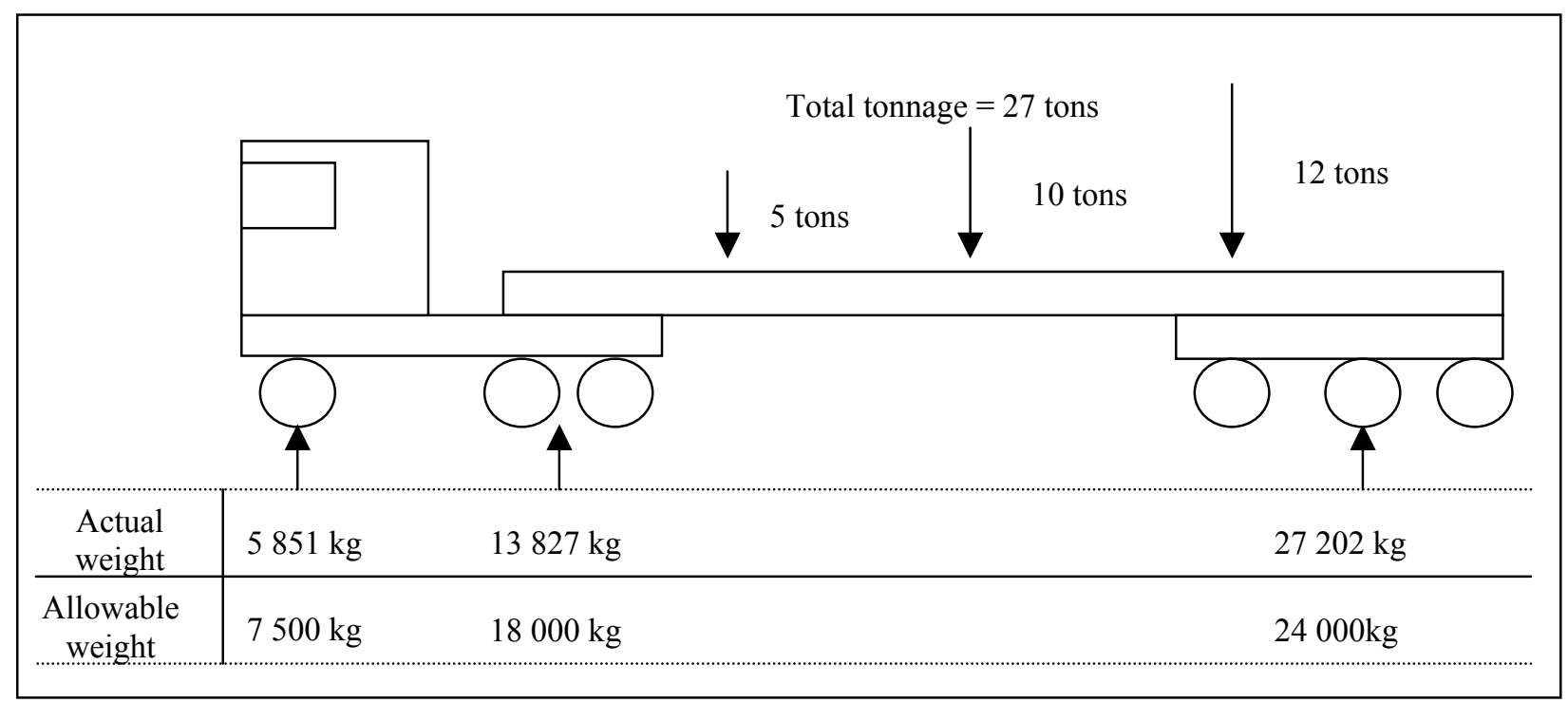

Figure 2(a): Representation of the problem concerning load layout and axle weights

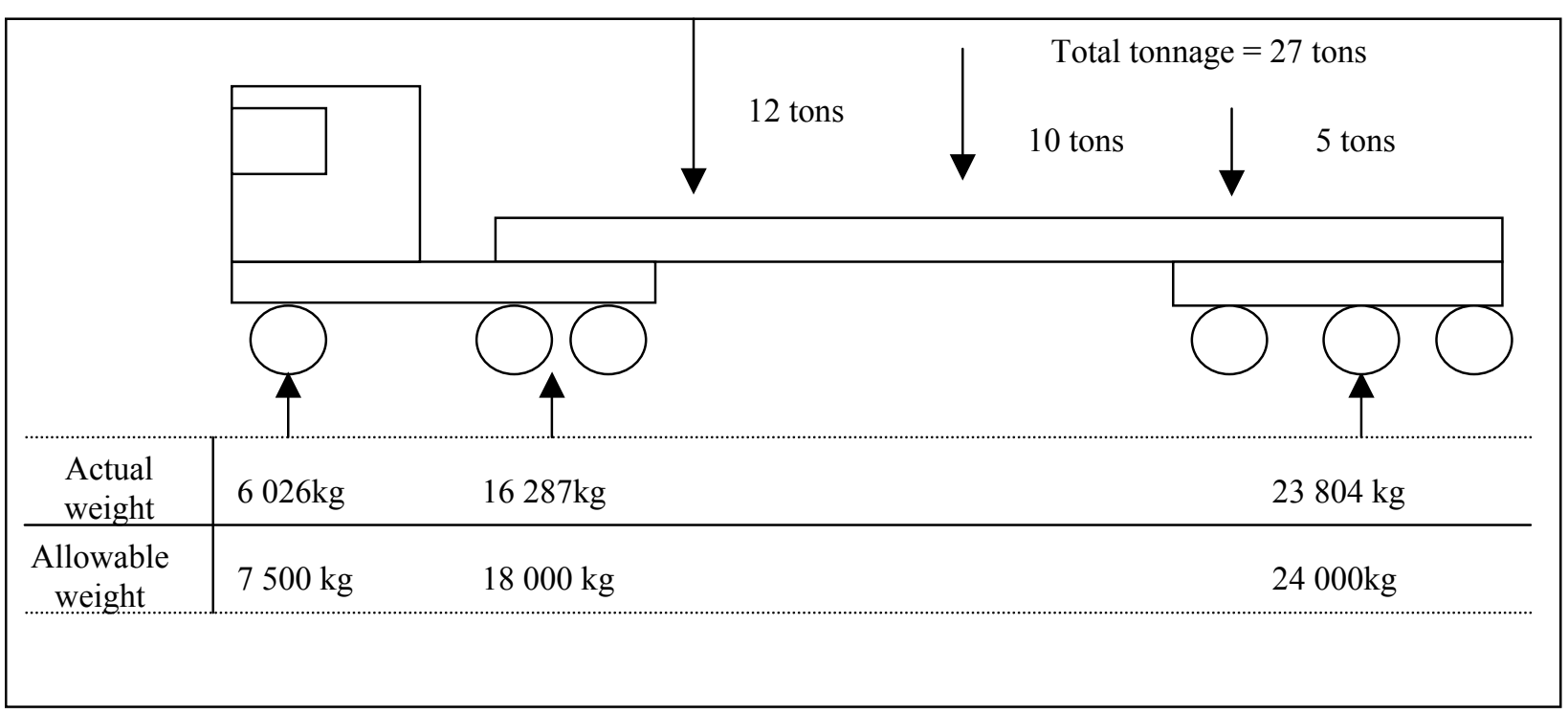

Figure 2(b): Rearrangement of load layout and associated axle weights

\section{THEORETICAL BASIS}

Various tools are needed to solve the problem. As suggested by Van Dyk [1] in her article on the philosophy-tool continuum, the approach to the problem will determine the techniques, which in turn will determine the required tools. Linear programming (LP) is a tool for solving optimization problems. Since the development of the simplex algorithm, LP has been used to solve optimization problems in industries as diverse as banking, education, petroleum and trucking [2]. Static equilibrium and the theory of moments form the basis of structural analysis. This will be used to calculate the axle weight and is therefore another tool that will be used. 


\section{Linear programming}

Linear programming consists of 2 parts, an objective function and a set of constraints. The objective function is a function that maximizes (usually profit) or minimizes (usually expenses) the objective function value by considering the values of the decision variables. The decision variables should completely describe the problem. A constraint limits the value of the decision variables and thus also influences the value of the objective function. Constraints also set the boundary for a feasible region in which an optimal solution to the problem may exist.

A general linear programming model, with $n$ decision variables, usually have the following form:

$$
\text { Maximize or Minimize }(\mathrm{z})=\sum_{i=1}^{n} c_{i} x_{i} \quad \text { (Objective function) }
$$

Subject To:

$$
\begin{aligned}
& \sum_{i=1}^{n} a_{i} x_{i} \leq K \\
& \sum_{i=1}^{n} b_{i} x_{i} \geq L
\end{aligned}
$$

In the above formulas $\mathrm{X}$ is a decision variable while $\mathrm{c}_{\mathrm{i}}, \mathrm{a}_{\mathrm{i}}$ and $\mathrm{b}_{\mathrm{i}}$ are the linear coefficients of the respective decision variables. The larger the value of the coefficients, the larger the effect of the associated decision variable.

\section{Theory of moments and Static Equilibrium}

As mentioned in the problem statement, it is necessary to formulate a mathematical equation that will determine the forces on the respective axle units. Such an equation can be developed using Newton's first law, which states, "A body will remain in motion, at its current speed and direction until an external force acts upon it" [3]. This is also true for a body in rest.

Any object or component must have a net balance of zero external forces and moments applied to it in order to remain at rest. When this type of situation occurs the object or component is said to be in static equilibrium, thus nothing is moving. This can be mathematically stated as $\sum \mathrm{F}_{\mathrm{y}}=0$ (All the forces acting vertically) and $\sum \mathrm{F}_{\mathrm{x}}=0$ (All the forces acting horizontally).

A moment can be quantified by multiplying the force with the distance between the force and the point of rotation. Mathematically it is shown as $\mathrm{M}=\mathrm{F} \times \mathrm{d}$.

\section{Government regulations on the payloads of vehicles}

The latest updates of the regulations on vehicle loading are published in the Government Gazette. Attention is given to the definitions of the regulations, since it has a direct bearing on 
the allowable axle limits. The type of suspension, number of axle units and the connection between the axle units, were considered for 28- and 30-ton trailers.

It was found that the trailers under consideration had one axle unit consisting of three axles, with pneumatic suspension, which were interconnected. This would require that the trailer and hauler conform to the legal limits stipulated in regulations 235, 236 and 239 [4]. These regulations allow for the following axle limits:

a) $1^{\text {st }}$ axle may not exceed $7500 \mathrm{~kg}$

b) $2^{\text {nd }}$ axles may not exceed $18000 \mathrm{~kg}$

c) $3^{\text {rd }}$ axles may not exceed $24000 \mathrm{~kg}$

\section{DEVELOPMENT OF THE SOLUTION}

This section describes the development of a practical solution using the concept discussed in the previous section. A suitable solution should ensure that the axle weights are within government limits and that the load has been placed optimally.

\section{Axle weight calculations}

The first step is to develop the mathematical model for determining the axle load. The trailer can be modeled as a beam, which is supported on a roller (rear axles) and a hinge ( $5^{\text {th }}$ wheel).

The effects of the trailer's rear axles are removed from the equations and added when the moment calculation has been completed, for they have no moment effect, as their work line cuts the moment center. The general load layout of a 28 - and 30-ton trailer and the resultant forces are displayed in Figure 3.

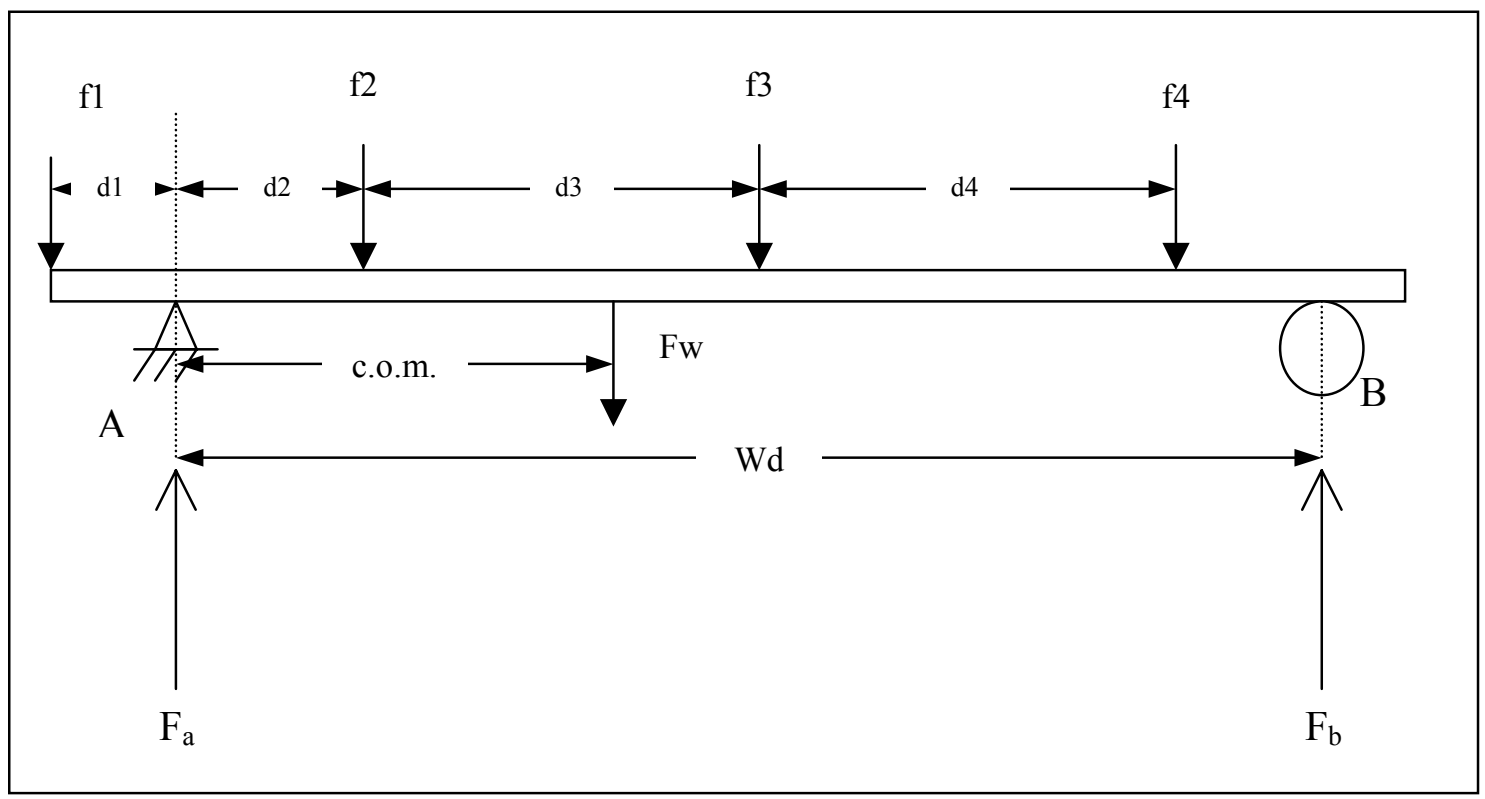

Figure 3: Free Body Diagram (FBD) of a beam model for a 28- or 30-ton trailer 
Definitions of elements in the formulae that follow:

$\mathrm{W}_{1-4}=$ the mass of the glass packs (Known)

$\mathrm{f}_{1-4}=$ force exerted by a glass pack (Known)

$\mathrm{F}_{\mathrm{a}, \mathrm{b}} \quad=$ reaction forces to $\mathrm{f}_{1-4}$ (Unknown)

$\mathrm{F}_{\mathrm{w}} \quad=$ the mass of trailer without wheels and suspension (Known)

c.o.m. = center of mass of trailer (Known)

$\mathrm{F}_{\mathrm{tt}}=$ total force exerted by the trailer's rear axle group (Weigh bridge reading)

$\mathrm{W}_{\mathrm{d}}=$ the force distance between the $5^{\text {th }}$ wheel and the rear trailer axles (Known)

$\mathrm{d}_{1-4}=$ distance between forces (Known)

g = gravitational constant $(\mathrm{g}=9.8)$

Using the FBD (free body diagram) in figure 3 and the definitions, it is possible to solve for $\mathrm{F}_{\mathrm{a}}$ and $\mathrm{F}_{\mathrm{b}}$. From static equilibrium it is known that $\sum \mathrm{F}=0$ (sum of all the forces) and $\sum \mathrm{M}=0$ (sum of all the moments). The mathematical model for the trailers can be written as:

$\mathrm{F}_{(1-4)}=\mathrm{W}_{(1-4)} \times \mathrm{g}$

$\sum \mathrm{F}_{\mathrm{y}}=0 \quad \downarrow+($ Down is taken as positive $)$

$\left(f_{1}+f_{2}+f_{3}+f_{4}+f_{w}\right)-\left(F_{a}+F_{b}\right)=0$

$\left(f_{1}+f_{2}+f_{3}+f_{4}+f_{w}\right)=\left(F_{a}+F_{b}\right)$

$\sum \mathrm{M}_{\mathrm{A}}=0+($ Clockwise is taken as positive $)$

$-\left(f_{1} \times d_{1}\right)+\left(f_{2} \times d_{2}\right)+\left(f_{3} \times\left(d_{3}+d_{2}\right)\right)+\left(f_{4} \times\left(d_{4}+d_{2}+d_{3}\right)\right)+\left(F_{w} \times c o m\right)-\left(F_{b} \times W_{d}\right)=0$

$F_{b}=\left[-\left(f_{1} \times d_{1}\right)+\left(f_{2} \times d_{2}\right)+\left(f_{3} \times\left(d_{3}+d_{2}\right)\right)+\left(f_{4} \times\left(d_{4}+d_{2}+d_{3}\right)\right)+\left(F_{w} \times c o m\right)\right] / W_{d}$

It is possible to solve for $\mathrm{F}_{\mathrm{b}}$ using equation 2 since all the values on the right-hand-side (RHS) of the equation are known. Once the value of $F_{b}$ is calculated the value of $F_{a}$ can be determined by substituting $F_{b}$ into equation 1 .

$\mathrm{F}_{\mathrm{tt}}=\mathrm{F}_{\mathrm{b}}+$ Mass of trailer rear axle mass

Equation 3 is used to calculate the total axle load as measured by a weighbridge. If this is not done, it will be found that the calculated axle masses are less than the actual axle mass.

The same method that was followed to calculate the reaction loads for the trailers can be applied to calculate the axle loads of the hauler. Figure 4 shows the FBD for a hauler. 


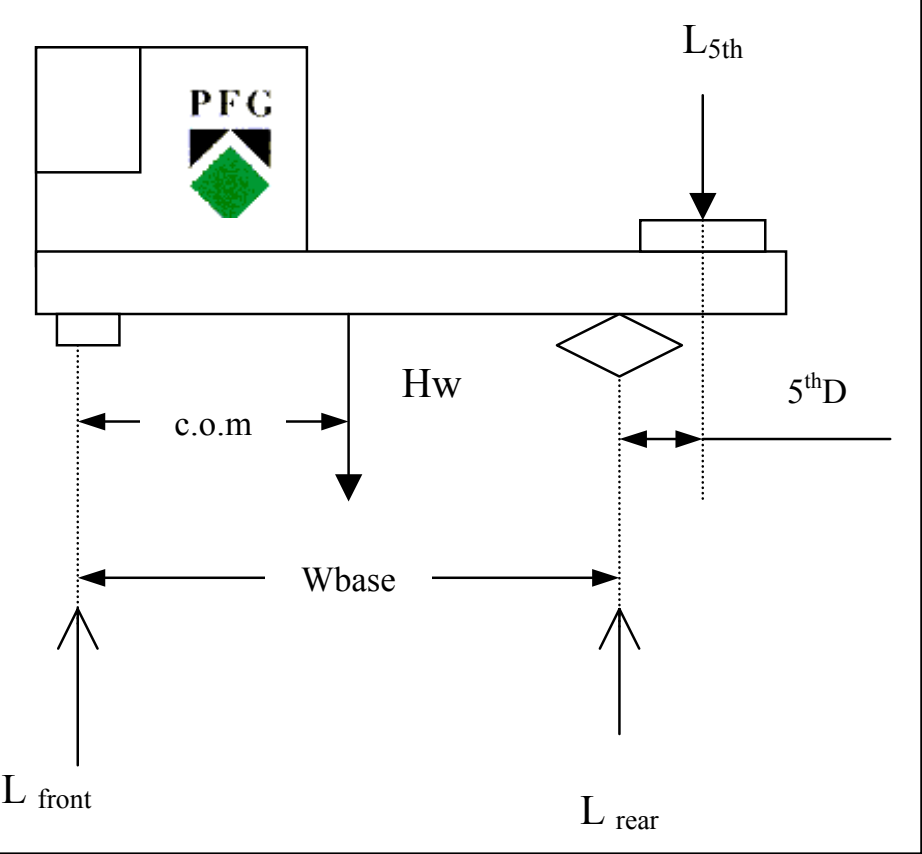

Figure 4: FBD for a hauler

Definitions of elements in the formulae that follow:

$\mathrm{L}_{\text {front }}=$ the axle load on the steering axle of the hauler (also known as horse1) (Unknown)

$\mathrm{T}_{\text {front }}=$ the total load as measured by the weighbridge

$\mathrm{L}_{\text {rear }}=$ the axle load on the drive axle of the hauler (also known as horse2) (Unknown)

$\mathrm{L}_{5 \text { th }} \quad=$ the $5^{\text {th }}$ wheel load exerted by the trailer, same as $\mathrm{F}_{\mathrm{a}}$ (Known)

$\mathrm{T}_{\text {rear }}=$ the total load as measured by the weighbridge

$\mathrm{H}_{\mathrm{w}} \quad=$ the mass of the hauler without wheels and suspension (Known)

c.o.m. = the center of mass of the hauler

Using the FBD (Figure 4) and the above definitions, it is possible to solve for $\mathrm{L}_{\text {front }}$ and $\mathrm{L}_{\text {rear }}$. The mathematical model for the hauler is as follows:

$\sum F=0$

$\mathrm{L}_{5 \text { th }}+\mathrm{Hw}=\mathrm{L}_{\text {front }}+\mathrm{L}_{\text {rear }}$

and

$\sum \mathrm{M}_{\mathrm{A}}=0$

$\mathrm{L}_{5 \text { th }} \times($ Wbase +5 thD $)+\mathrm{H}_{\mathrm{w}} \times$ c.o.m $=\mathrm{L}_{\text {rear }} \times$ Wbase

The values of $\mathrm{L}_{\text {front }}$ and $\mathrm{L}_{\text {rear }}$ can be obtained in the same manner as for the trailer. Equations 6 and 7 are used to add the effect of the wheels and axles for the hauler. 
$\mathrm{T}_{\text {front }}=\mathrm{L}_{\text {front }}+$ front axle and wheel effect

$\mathrm{T}_{\text {rear }}=\mathrm{L}_{\text {rear }}+$ rear axle and wheel effect

\section{Linear programming formulation}

A general formulation can be derived that will provide optimal load layouts, irrespective of the trailer type, number of loading zones or number of packs ordered. An assignment tableau is given in figure 5. This tableau is three-dimensional, since the solution should indicate which position should be loaded and with which type of glass.

In Figure 5 it can be seen that $\mathrm{X}_{\mathrm{ij}}$ represents the position in its respective loading zone. $\mathrm{C}_{\mathrm{ij}}$ is the associated cost or penalty for the loading position. The third axis represents the types of glass.

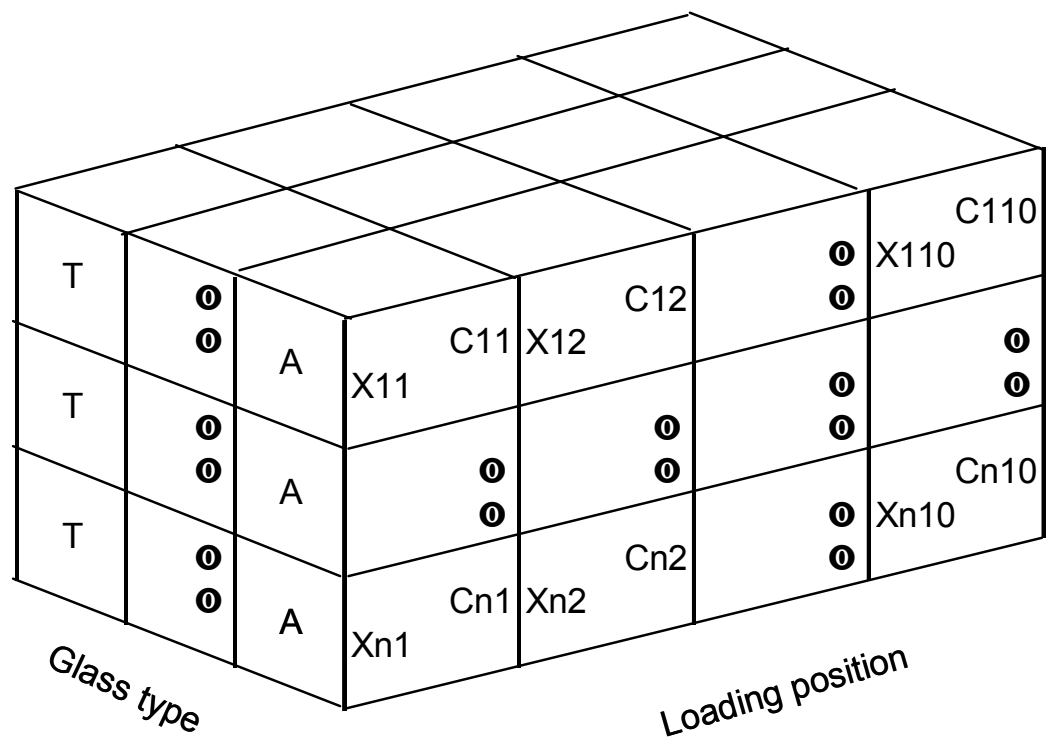

Figure 5: 3-Dimensional assignment tableau

The previous section shows that the axle force on the $5^{\text {th }}$ wheel and rear trailer axles can be calculated using the theory of moments and static equilibrium. The coefficients of the objective function will thus be the contribution to the axle mass of a pack of glass, considering both the rear axles, as well as the $5^{\text {th }}$ wheel. The objective is to minimize the axle loads exerted by the load. The forces exerted by the rear trailer axles are dependent on the force on the $5^{\text {th }}$ wheel and vice versa (equation (1) and equation (2)). Minimizing the one will maximize the other, which could produce axle loads above regulation. A constraint is thus needed to ensure that both axle weights are minimized. Putting a limit on the amount of mass that each zone is allowed to carry can achieve the required results.

To ensure that the larger packs are placed closest to the A frame, the value of the objective function coefficients increases as one moves to the edge loading positions. The manipulation of the objective function coefficients will ensure that the 1-ton difference between the two 
sides of the trailer are adhered to, as not to cause the trailer to tip over to one side, since the heaviest glass packs will be placed on the loading positions with the lowest coefficients. Thus $\mathrm{C}_{\mathrm{i} 1}=\mathrm{C}_{\mathrm{i} 10}>\mathrm{C}_{\mathrm{i} 2}=\mathrm{Ci}_{9}>\mathrm{Ci}_{3}=\mathrm{Ci}_{8}>\mathrm{Ci}_{5}=\mathrm{Ci}_{7}>\mathrm{C}_{\mathrm{i} 5}=\mathrm{C}_{\mathrm{i} 6}$

Let $\mathrm{X}_{\mathrm{IJK}}$ be the decision variable that denotes the location of a certain glass type in a certain position on the trailer, with I $\varepsilon$ [A..Z], J $\varepsilon$ [1..4] and $\mathrm{K} \varepsilon$ [1..10]. $\mathrm{W}_{\mathrm{I}}$ will denote the weight of the pack of glass $I, L_{I}$ the length of glass pack $I$ and $C_{J K}$ the effect of 1 ton of glass on the axles of the trailer. The model for each of the loading zones for a 28- and 30-ton trailer will have the general formulation, with $n$ equal to the number of loading zones:

$$
\min z=\sum_{I=A}^{Z} \sum_{J=1}^{n} \sum_{K=1}^{10} c_{J K} W_{I} X_{I J K}
$$

Subject to:

for $\mathrm{J} \varepsilon[1 . . \mathrm{n}]: \sum_{I=A}^{Z} \sum_{K=1}^{10} W_{I} X_{I J K} \leq$ Zone allowance

for I $\varepsilon$ [1.. pack types]: $\sum_{J=1}^{n} \sum_{K=1}^{10} X_{I J K}=$ Number of packs ordered

for $\mathrm{J} \varepsilon[1 . . \mathrm{n}]$ and $\mathrm{K} \varepsilon[1 . .10]: \sum_{I=A}^{Z} X_{I J K} \leq 1$

for $\mathrm{J} \varepsilon[1 . . \mathrm{n}]$ and $\mathrm{K} \varepsilon[1 . .5][6 . .10]$ :

$$
\sum_{I=A}^{Z}(\text { placement }) \quad\left(L_{I J K} X_{I J K}-L_{I} X_{I J(K-1)} \leq \text { Length Allowance }\right)
$$

for I $\varepsilon\left[1 .\right.$. pack types]; J $\varepsilon[1 . . \mathrm{n}]$ and $\mathrm{K} \varepsilon[1 . .10]: \quad \sum_{I=A}^{Z} \sum_{J=1}^{n} \sum_{K=1}^{10} X_{I J K}=\left[\begin{array}{ll}0 & 1\end{array}\right]$

Equation (9) ensures that the zone weight limitation is not exceeded. Equation (10) ensures that all the ordered packs are placed. Equation (11) ensures that only one pack is assigned to a loading position. Equation (12) ensures that differences between the lengths of each adjacent pack are less than the length allowance. "Placement" is a binary variable that is one, if the constraint should be enforced and 0 if not. The enforceability will depend on the placement of glass pack next to each other. Equation (13) ensures that the decision variable can only be 0 or 1.

The coefficients of the objective function will change, according to the number of loading zones and trailer types, i.e. the objective function for a 30-ton trailer with 10 glass packs would look different from one for a 28-ton trailer with 20 packs. Equation (9)'s right-handside constraint value will be dependant on the number of loading zones chosen, as well as the trailer type. Equation (10)'s right-hand-side constraint value will be dependant on the number 
of glass packs ordered for that specific glass type. Equation (11) will remain unchanged irrespective of the trailer type or number of loading zones. The right-hand-side value of equation (12) will be user defined.

\section{Practical application of the model}

Assume that the following load has to be optimized:

7 packs of $3 \mathrm{~mm} \times 1830 \mathrm{~mm} \times 1220 \mathrm{~mm}(803 \mathrm{~kg})$

7 packs of $3 \mathrm{~mm} \times 2000 \mathrm{~mm} \times 1605 \mathrm{~mm}(1154 \mathrm{~kg})$

Length allowance $=0$

Zone constraint $=17350 \mathrm{~kg}$

Number of zones $=2$

Define $X_{i}$, the decision variable, as 1 , if the glass pack is placed in zone 1 , where (i) $\varepsilon$ [1..10] for zone 1 and (i) $\varepsilon[11 . .20]$ for zone 2 . The element section represents the number of loading positions in the zone. It should be noted that $X_{i j}=X_{i}$, the only difference between the two is the indexing of the decision variable. $X_{i}$ is a more sequential method of numbering, than the matrix convention $X_{\mathrm{ij}}$. To retain the three-dimensional functionality of the model, another variable called T\#Z\& will be used, where \# is the type of glass and \& the zone. T2Z2 would thus reads as type 2 in zone 2 . The reason for this notation is that it enables ease of reading the model.

The objective function will thus be the following:

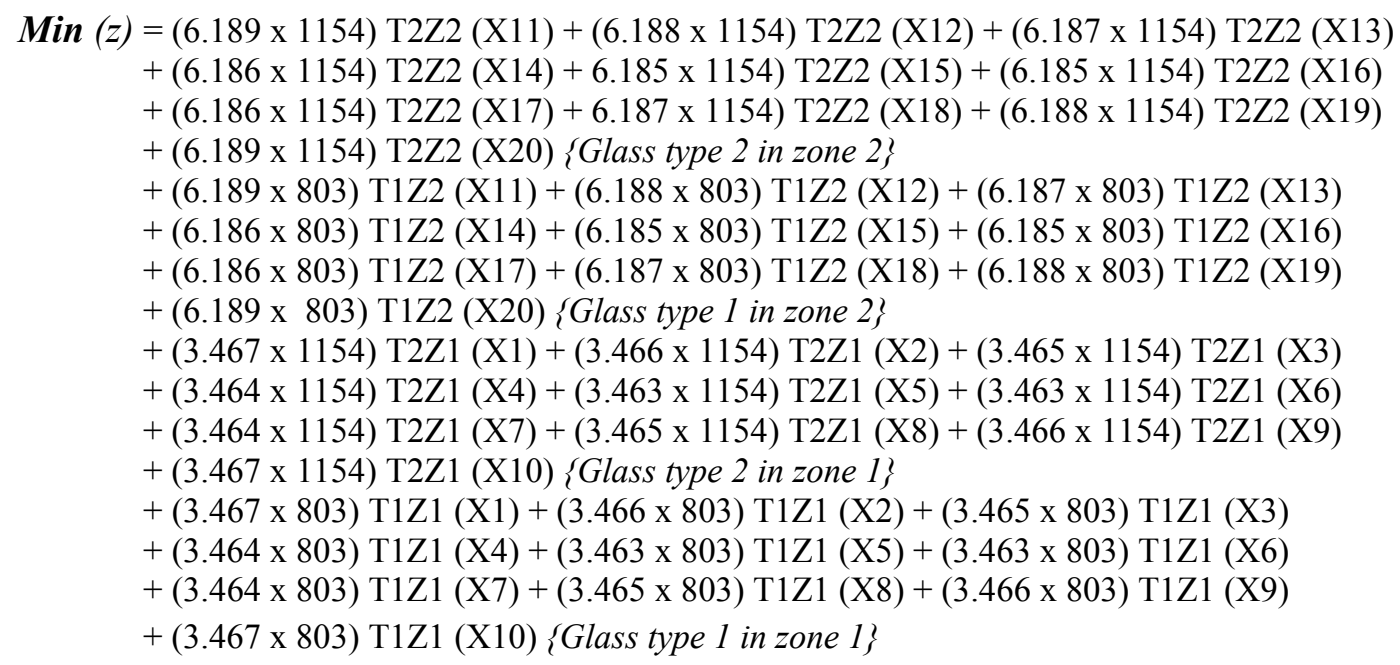

From the objective function it can be seen that it minimizes the function value. Glass type 2 will produce the highest coefficients in zone 2 , and will thus not be assigned to zone 2 , but rather to zone 1, thus placing the glass in the most optimal position.

The constraints can be defined as follows:

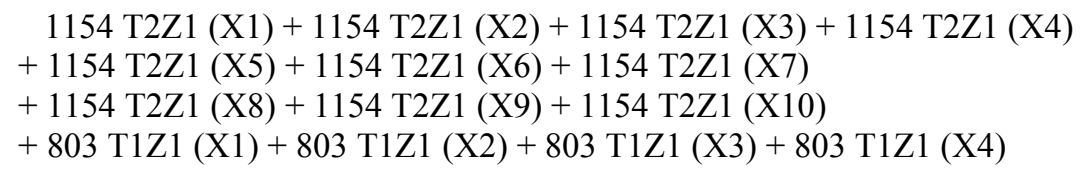




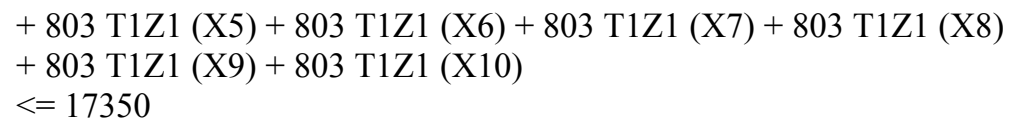

The above constraint ensures that the zone limit is not exceeded

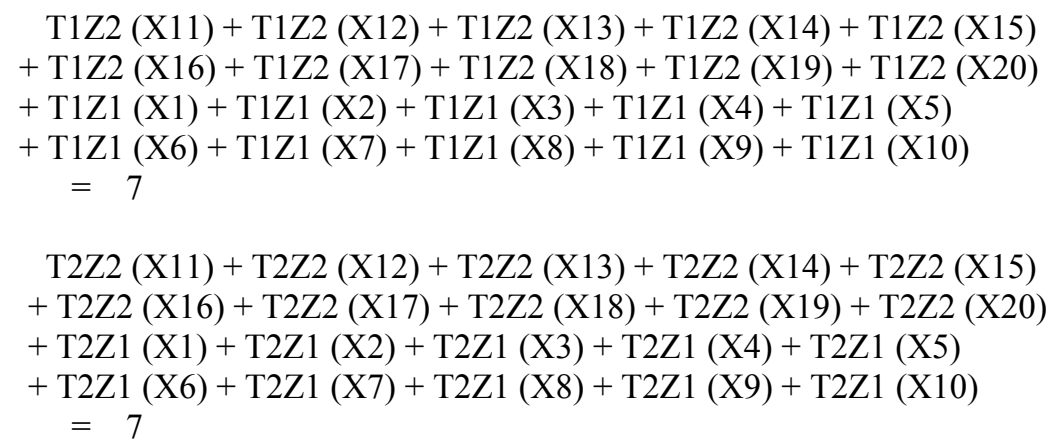

The above two constraints ensure that all the ordered packs are placed, by summing all the assignment values for both zones, thus $7 \times \mathrm{T} 1 \mathrm{Z}(1$ or 2$)\left(\mathrm{X}_{\mathrm{i}}\right)=$ all the ordered packs of that type.

$\mathrm{T} 2 \mathrm{Z} 1(\mathrm{X} 1)+\mathrm{T} 1 \mathrm{Z} 1(\mathrm{X} 1)<=1$

$\mathrm{T} 2 \mathrm{Z} 2(\mathrm{X} 20)+\mathrm{T} 1 \mathrm{Z} 2(\mathrm{X} 20)<=1$

The above two constraints are the first and last of a set of equations that ensure that only one pack is placed in a loading position. This is achieved by summing all the possible instances of a glass pack being loaded to a position and setting it equal to 1 .

The last constraint should ensure that the base lengths of each of the glass packs are acceptable for the respective zones. A Boolean variable is introduced to ensure that the length constraint is not enforced if a loading position is not used. The constraint will thus be a function of the placement of glass packs. The constraints are as follows:

$2000 \mathrm{~T} 2 \mathrm{Z} 1(\mathrm{X} 1)+1830 \mathrm{~T} 1 \mathrm{Z} 1(\mathrm{X} 1)=\mathrm{L} 1$

$2000 \mathrm{~T} 2 \mathrm{Z} 1(\mathrm{X} 2)+1830 \mathrm{~T} 1 \mathrm{Z} 1(\mathrm{X} 2)=\mathrm{L} 2$

$\mathrm{T} 2 \mathrm{Z} 1(\mathrm{X} 1)+\mathrm{T} 1 \mathrm{Z1}(\mathrm{X} 1)=$ placement 1

placement $1 *(\mathrm{~L} 2-\mathrm{L} 1)<=0$

$$
(\mathrm{L} 2-\mathrm{L} 1)>=0
$$

Constraint 12.1 and 12.2 assign the length of the glass type in the position to a variable. Constraint 12.3 determines whether the length constraints should be enforced or not. Constraint 12.4 is the length constraint. Constraint 12.5 ensures that a smaller pack is not placed before a larger pack. There exist such a set of constraints for each of the loading positions.

A linear, non-linear and integer programming solver called HYPER LINGO 7 with NONLINEAR Extension was used to solve the problem. The result is graphically represented in Figure 6. 


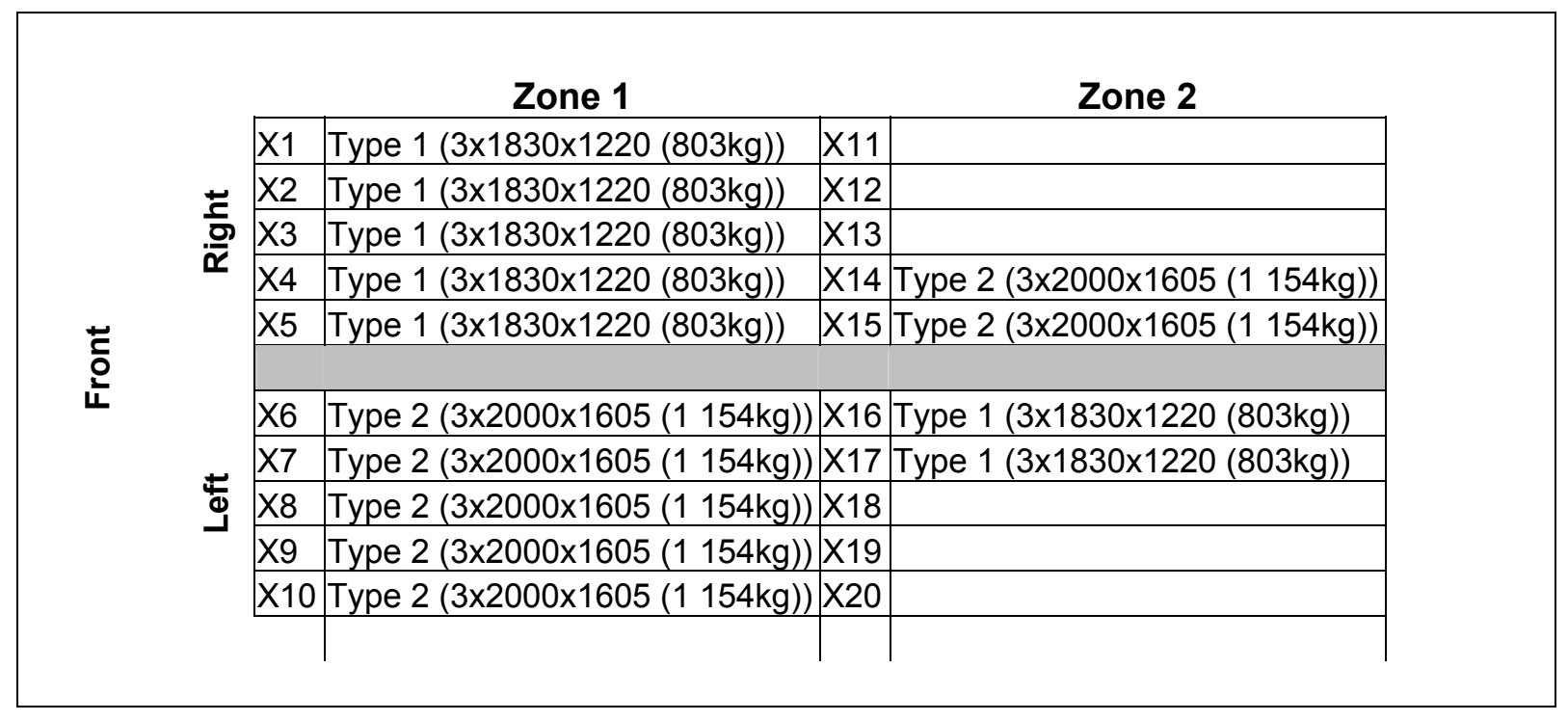

Figure 6: Graphical interpretation of the solution found

Using the previously defined equations 1 to 3 , the axle weight can be determine as follows: $((7 \times 803) g+(7 \times 1154) g)=\left(F_{a}+F_{b}\right)$

and

$\mathrm{F}_{\mathrm{b}}=[[5(803 \times[3.16+(1.83 / 2))]] \mathrm{g}+[2(1154) \times[(3.16+0.5)+((1.83 / 2)+(2.0 / 2))]] \mathrm{g}+$ $[5(1154 \times[3.16+(2.0 / 2))] \mathrm{g}+[2(803) \times[(3.16+0.5)+((2.0 / 2)+(1.83 / 2))]] \mathrm{g}+(8300 \mathrm{x}$ $5.8)] / 8.3=\underline{11935 \times \mathrm{g}}$

$\mathrm{Ftt}=\mathrm{Fb}+$ Mass of trailer rear axle mass $=11935+3000=\underline{14935 \mathrm{~kg}}$

The answers are given in kilograms.

From equation $1 \mathrm{Fa}$ can be determined as follows:

$((7 \times 803) g+(7 \times 1154) g)=\left(F_{a}+F_{b}\right)$

$\mathrm{F}_{\mathrm{a}}=\underline{14295 \mathrm{~kg}}$

Using the previously defined equations 4 to 7 , the axle force for the hauler can be calculated. It is found that the rear hauler axle weight is $14295 \mathrm{~kg}$ and the front is $6561 \mathrm{~kg}$. From the calculations it can be seen that the load can be increased as the total axle masses are within government specifications.

\section{PACKAGING OF THE SOLUTION}

The above two models were integrated into an order entry information system. An order has to pass basic validation rules before it can be optimized. LINGO7 is used to extract the order data from the information database. The load is then optimized and the result exported to the database. The results are graphically represented and printed with the picking lists for the loading personnel. The load layout is thus optimized with the press of a single command button. 


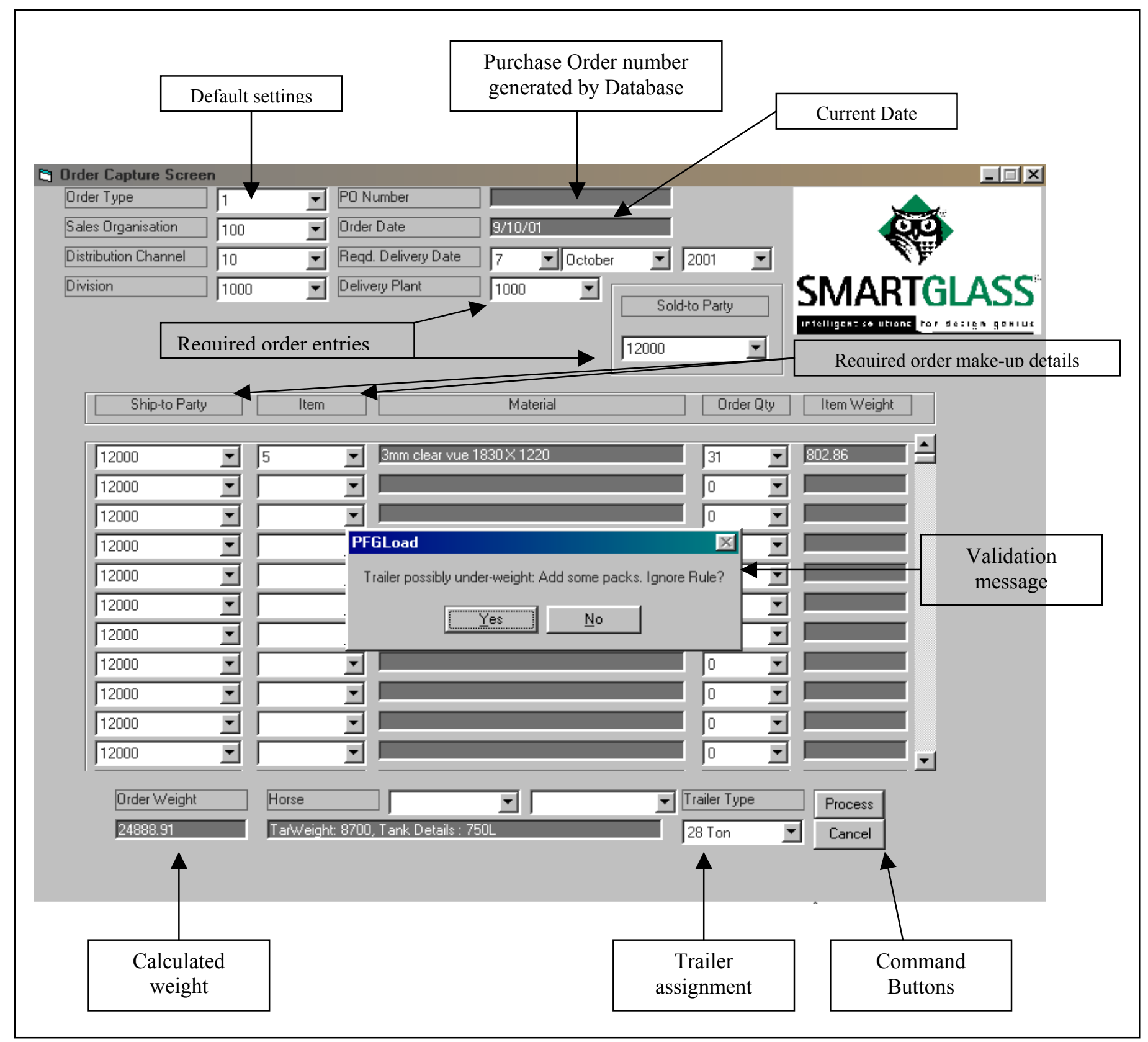

Figure 7: First stage order capturing screen

Figure 7 shows the order entry screen. After the order has been captured, it is automatically sent to LINGO 7 for optimization. The results are then graphically presented as in Figure 8 . The load layout can then be printed for the loading personnel. 


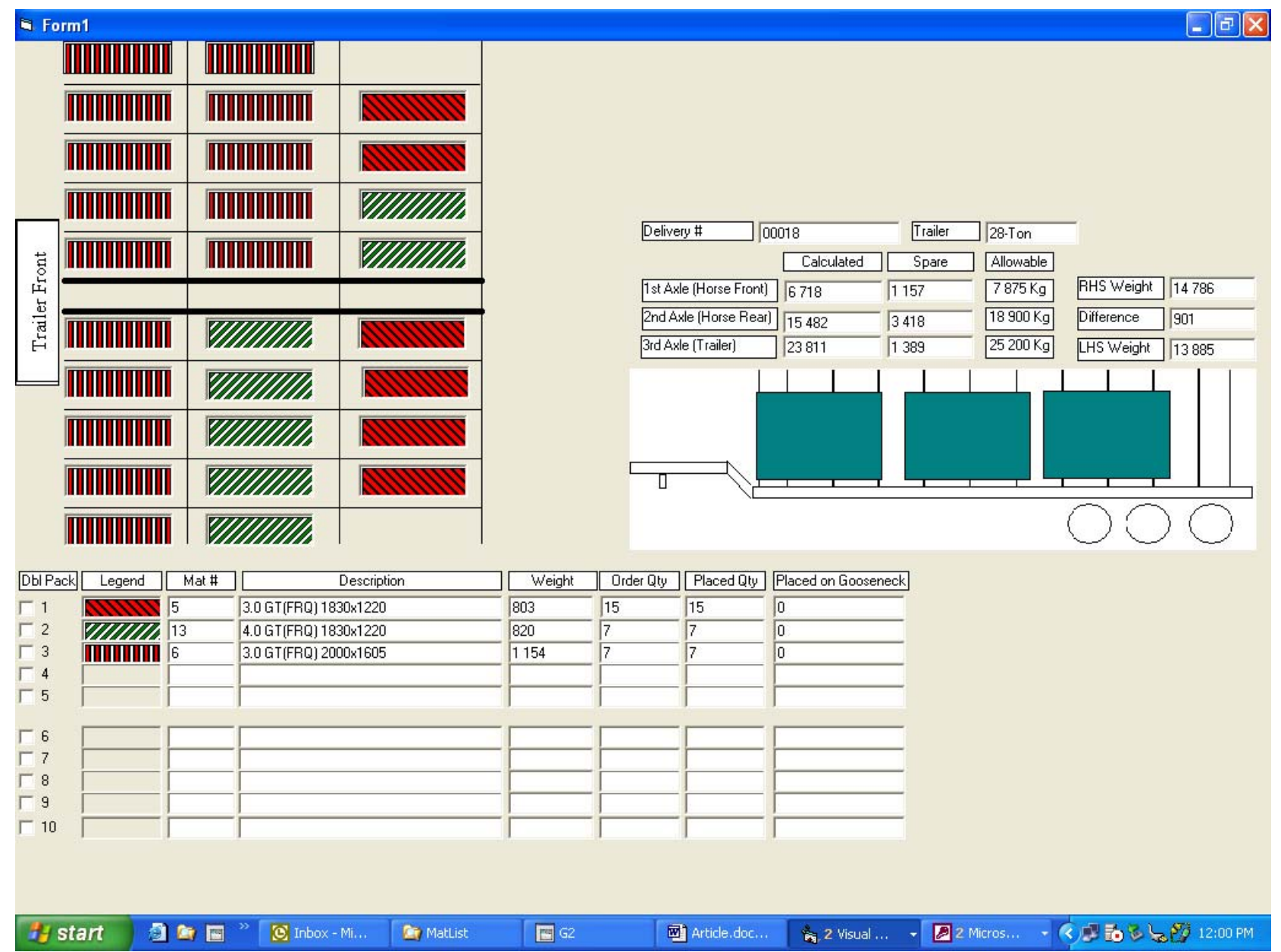

Figure 8: Optimal load layout

\section{CONCLUSION}

Some of the benefits that can be gained from the implementation of the model are the following:

- The lead-time for the loading process is shortened. (Loading can take up to 2 hours.)

- With the optimization of the load layout a higher payload can be shipped, since the axle mass is predetermined.

- The knowledge of loading a trailer resides in the information database and no longer with the loading personnel.

- The model will enable PFG to validate in real-time if an order is transportable, which will enable the implementation of an e-commerce site. 


\section{REFERENCES}

[1] Van Dyk, L. (2001). The Philosophy-Tool continuum: Providing structure to industrial engineering concepts, South African Journal of Industrial Engineering,Vol 12, No. 2, November 2001.

[2] Winston, L.W. (1997). Operations research: Applications and Algorithms, International Thomson Publishing, United States of America, p49-123, p464-492.

[3] Riley, W.F. (1995), Engineering Mechanics and Statics, Prentice Hall, United States of America, p35.

[4] Government Gazette. May 2000. 